\title{
O trabalho com etnopedologia, educação sobre solos e ensino de ciências da natureza no PIBID Educação do Campo da UFPR Litoral
}

\author{
Work with ethnopedology, education on soils and teaching nature sciences \\ in PIBID Rural Education of UFPR Litoral
}

\begin{abstract}
Ehrick Eduardo Martins Melzer (ehrickmelzer@ufpr.br)
Universidade Federal do Paraná (UFPR), Setor Litoral, Licenciatura em Educação do Campo: Ciências da Natureza
\end{abstract}

Gilson Walmor Dahmer (gwdahmer@gmail.com)

Universidade Federal do Paraná (UFPR), Setor Litoral, Licenciatura em Educação do Campo: Ciências da Natureza

Resumo: Apresentamos neste trabalho o recorte em uma ação dentro do Núcleo de Iniciação à Docência (NID) do Programa Interinstitucional de Iniciação à Docência (PIBID), edição de 2018-2020, que ocorreu no curso de Licenciatura em Educação do Campo: Ciências da Natureza (LECAMPO) da Universidade Federal do Paraná (UFPR). A referida ação embasou-se na construção coletiva com bolsistas e professores colaboradores de uma oficina sobre educação em solos denominada Solos ComCiência. O objetivo principal da ação foi mobilizar saberes camponeses sobre solos para dialogar com conhecimentos científicos buscando contextualizar conceitos de química e física e reforçar a importância dos solos na manutenção da vida e desenvolvimento da sociedade. Neste sentido, nosso objetivo é trazer um relato da construção desta ação e de seus resultados junto às comunidades escolares do Colégio Estadual do Campo Hiram Rolim Lamas (Antonina-PR) e Colégio Estadual do Campo Ilha das Peças (Guaraqueçaba-PR). Estas ações foram desenvolvidas em três momentos. O primeiro foi de planejamento da ação com o levantamento da demanda pelas unidades escolares em conversa com professores, estudantes e bolsistas nos dois colégios. O segundo momento foi com o desenvolvimento da oficina em um dia específico previsto pelas direções das escolas. No terceiro momento foi desenvolvido o trabalho pedagógico com os bolsistas e professores supervisores nas aulas de Ciências da Natureza (Química, Física e Biologia). Esta ação findou-se com uma palestra que foi ministrada sobre alimentação e segurança alimentar e a importância da agricultura agroecológica finalizando o processo pedagógico construído com as duas unidades escolares. Ressalta-se que a ação gerou reflexões, questionamentos e produtos pedagógicos elaborados coletivamente com as escolas tais como: sequências didáticas, maquete de experimentação para observar a infiltração e retenção de água no solo e um pôster sobre o tema em questão que atualmente fazem parte do acervo digital do PIBID Educação do Campo.

Palavras-chave: Educação do Campo; Ensino de Ciências; Agroecologia; Solo.

Abstract: We present in this work the cut in an action within the Teaching Initiation Nucleus (NID) of the Interinstitutional Program for Teaching Initiation (PIBID), edition of 2018-2020, which took place in the Course of Education in the Field: Natural 
Sciences (LECAMPO) of the Federal University of Paraná (UFPR). This action was based on the collective construction with scholars and collaborating teachers of a workshop on soil education called Solos ComCiência. The main objective of the action was to mobilize peasant knowledge about soils to dialogue with scientific knowledge, seeking to contextualize concepts of chemistry and physics and reinforce the importance of soils in maintaining life and the development of society. In this sense, our objective is to bring a report of the construction of this action and its results to the school communities of the Colégio Estadual do Campo Hiram Rolim Lamas (Antonina-PR) and Colégio Estadual do Campo Ilha das Peças (Guaraqueçaba-PR). These actions were developed in three moments. The first was to plan the action with the survey of demand for school units in conversation with teachers, students and scholarship holders in both schools. The second moment was with the development of the workshop on a specific day foreseen by the school boards. In the third moment, pedagogical work was developed with scholarship holders and supervising teachers in the classes of Natural Sciences (Chemistry, Physics and Biology). This action ended with a lecture that was given on food and food security and the importance of agroecological agriculture, ending the pedagogical process built with the two school units. It is noteworthy that the action generated reflections, questions and pedagogical products developed collectively with schools such as: didactic sequences, experimentation model to observe the infiltration and retention of water in the soil and a poster on the subject in question, which are currently part of the project. digital collection of PIBID Educação do Campo.

Keywords: Rural Education; Science teaching; Agroecology; Ground.

\section{INTRODUÇÃO}

O Programa Interinstitucional de Iniciação à Docência (PIBID) é um programa em vigência por meio da Coordenação de Aperfeiçoamento de Pessoal de Nível Superior (CAPES) fomenta propostas de articulação da Universidade com os ambientes profissionais escolares para a iniciação à docência. Neste contexto insere-se às Licenciaturas em Educação do Campo (LEDOCS) que entram nos editais a partir da criação do PIBID Diversidade e, atualmente, fazem parte dos cursos elegíveis para desenvolvimento de propostas.

Assim, este artigo busca apresentar a constituição de uma proposta de atividade por dentro do Núcleo de Iniciação à Docência (NID) da Licenciatura em Educação do Campo - Ciências da Natureza (Lecampo ${ }^{1}$ ) da Universidade Federal do Paraná (UFPR), mais especificamente no Setor Litoral (SL) que atende aos sete municípios do litoral paranaense com seus quatorze (14) cursos de graduação.

\footnotetext{
${ }^{1}$ Neste artigo iremos considerar LEDOCS como o termo geral para designar Licenciatura em Educação do Campo. Para a Licenciatura em Educação do Campo: Ciências da Natureza da UFPR do Setor Litoral usaremos o termo Lecampo que refere-se a sigla que o curso utiliza institucionalmente.
} 
Desta forma, parte-se da seguinte questão: como se estruturou a proposta de educação em solos, a partir da etnopedologia, no NID Educação do Campo? A partir desta temos por base que a meta deste trabalho é fazer uma apresentação do projeto PIBID Educação do Campo conduzido na Lecampo - UFPR trazendo um relato da construção desta ação e de seus resultados junto às comunidades escolares do Colégio Estadual do Campo Hiram Rolim Lamas (Antonina-PR) e Colégio Estadual do Campo Ilha das Peças (Guaraqueçaba-PR).

Assim, este trabalho organiza-se em quatro seções: i) PIBID e o NID Educação do Campo que busca apresentar uma contextualização histórica do PIBID e a concepção do NID Educação do Campo na UFPR, Setor Litoral; ii) Etnopedologia e o diálogo de saberes para a construção da agroecologia que tem como objetivo de apresentar as bases teóricas epistemológicas do diálogo de saberes, etnopedologia, agroecologia e educação do campo que orientaram o trabalho prático na construção das pontes de relações entre os saberes sobre solos e científicos escolares; iii) A construção da oficina solo comciência que busca apresentar ao leitor o movimento construído nas escolas com o PIBID para construção da proposta pedagógica como um todo e iv) O diálogo da química, física e biologia com o estudo sobre solos e segurança alimentar que tem como objetivo apresentar como teoricamente se construiu dentro do território prático as relações, diálogo de saberes, entre solos com química, física e biologia nas escolas do campo no litoral paranaense.

\section{PIBID E O NID EDUCAÇÃO DO CAMPO}

O PIBID foi uma ação do Ministério da Educação (MEC) com a CAPES para estimular a formação de docentes para a educação básica. A ideia colocada era de fazer um programa paralelo ao Programa Interinstitucional de Bolsas de Iniciação Científica (PIBIC) com foco no aprimoramento de docentes em formação inicial, proporcionando ao mesmo tempo formação continuada a professores nas escolas, uma vez que estes seriam supervisores.

A primeira edição apresentada em 2007 previa a formação de NID com bolsistas estudantes de graduação recebendo bolsas de 400 reais, professores de escolas que atuariam como supervisores recebendo 730 reais, coordenadores de área e institucionais que recebiam 1500 reais. Além destes valores convertidos em bolsas, cada proposta receberia um valor corrente para despesas de deslocamento, organização de eventos e 
para custeio de material necessário para desenvolvimento das atividades nas escolas e cursos de formação. Ao todo foram nove edições com tempo de execução das propostas de dois anos cada, mostrando a consolidação da política de incentivo à docência.

Porém, apesar do tempo largo de execução da política o que se observa é que a cada edição o PIBID foi encolhendo no quantitativo de bolsas concedidas, como nos cortes de verbas para apoio no transporte, aquisição de equipamentos e no desenvolvimento de eventos voltados à iniciação à docência nas redes de ensino e na universidade. Ou seja, observa-se um gradativo encolhimento da ação, fruto da mudança do cenário político e na correlação de forças dentro do MEC e da CAPES.

A Educação do Campo começa a fazer parte do PIBID em 2013 com o lançamento do edital do PIBID Diversidade, programa voltado para habilitação de LEDOC para compor propostas de iniciação a docência em todo o Brasil. De acordo com Santos (2009) o PIBID Diversidade vem com o intuito de dar aporte financeiro de bolsas para os estudantes de Educação do Campo como forma de manutenção e fortalecimento financeiro ao edital Programa de Apoio à Formação Superior em Licenciatura em Educação do Campo (PROCAMPO) edital de 2009. Melzer (2020) coloca que o PIBID veio para auxiliar as LEDOC a garantir recursos de bolsa para os estudantes, o que não era previsto no custeio das propostas do PROCAMPO.

A Lecampo da UFPR, Setor Litoral, só foi participar de uma proposta PIBID no edital 2018. Neste ano, foi proposto por um grupo de professores do curso o NID Educação do Campo organizado sobre o eixo das Ciências da Natureza (Química e Física) e embasado na proposta da Educação Agroecológica e do Diálogo de Saberes.

O grande diferencial desta proposta para outras experiências PIBID está no formato de organização da experiência, na abrangência e no formato de ação que foi organizado sob o eixo de Projetos de Aprendizagem (PA) do Projeto Político Pedagógico (PPP) do Setor Litoral.

Antes de entrarmos na descrição do desenho pedagógico e metodológico do NID há a necessidade de se explicar as peculiaridades do PPP do Setor Litoral que ficou conhecido como UFPR Litoral e do Projeto Pedagógico de Curso (PPC) da Licenciatura em Educação do Campo (LECAMPO). O PPP do Setor Litoral (UFPR LITORAL, 2014) é baseado na proposta de Educação por Projetos que se organiza em três eixos 
distintos: Fundamentos Teóricos Práticos (FTP), Interações Culturais e Humanísticas (ICH) e Projetos de Aprendizagem (PA).

Os FTPs têm como objetivo fazer a introdução e o desenvolvimento dos saberes comuns a formação do curso e que vai ao encontro dos anseios profissionais de aprendizagem dos estudantes. Desta forma, são organizados em formato modular prevendo trabalho pedagógico colaborativo entre professores e estudantes dentro da lógica de complementaridade dos saberes e da docência compartilhada. Ou seja, o módulo, em oposição da disciplina, busca trabalhar a totalidade dentro das particularidades com um processo de inteligência coletiva colaborativa construído nas relações pedagógicas que se constroem na sala de aula e em outros ambientes educativos.

As ICHs têm como objetivo primordial desenvolver a autonomia propositiva dos educandos, curricularmente, com o intuito de possibilitar a interação entre diferentes cursos no Setor Litoral. Podemos compreender como um espaço de socialização do conhecimento sob diferentes perspectivas. O ponto principal deste eixo pedagógico é a não necessidade de um professor regente à frente do processo, cada discente e docente participa contribuindo com suas pesquisas e seus conhecimentos ao eixo. Este também possibilita a participação da comunidade externa seja ensinando alguma prática social de referência, ou seja, participando como aprendente no processo.

Já o PA tem como objetivo pedagógico o desenvolvimento de uma proposta de pesquisa e ensino que parte da curiosidade epistemológica do estudante. Ou seja, neste eixo pedagógico o educando propõe uma ação pedagógica que pode ir desde um simples estudo até uma ação na realidade concreta de sua comunidade.

Neste contexto de projeto diferenciado de educação superior é que se constitui a Lecampo no Setor Litoral, o curso conta com um projeto pedagógico que busca construir um duplo movimento de ocupação da universidade e desterritorialização do alcance das estruturas contidas em Matinhos para municípios do Vale do Ribeira (Cerro Azul e Adrianópolis), Lapa (Assentamento Contestado na Escola Latino Americana de Agroecologia) e litoral (Morretes, Antonina, Paranaguá e Guaraqueçaba) chamado de itinerância pedagógica. Nesta lógica formativa estabeleceu-se o regime de alternância com a constituição dos tempos pedagógicos de Universidade (TU) e Comunidade (TC) 
e o de itinerância com o desenvolvimento do TU nos mais diversos territórios de lutas pelas terras, águas e florestas com idas a Universidade para atividades coletivas e laboratórios de aprendizagem. Melzer (2020) faz o mapeamento deste alcance do curso a partir dos dados do Censo da Educação Superior de 2009 a 2018:

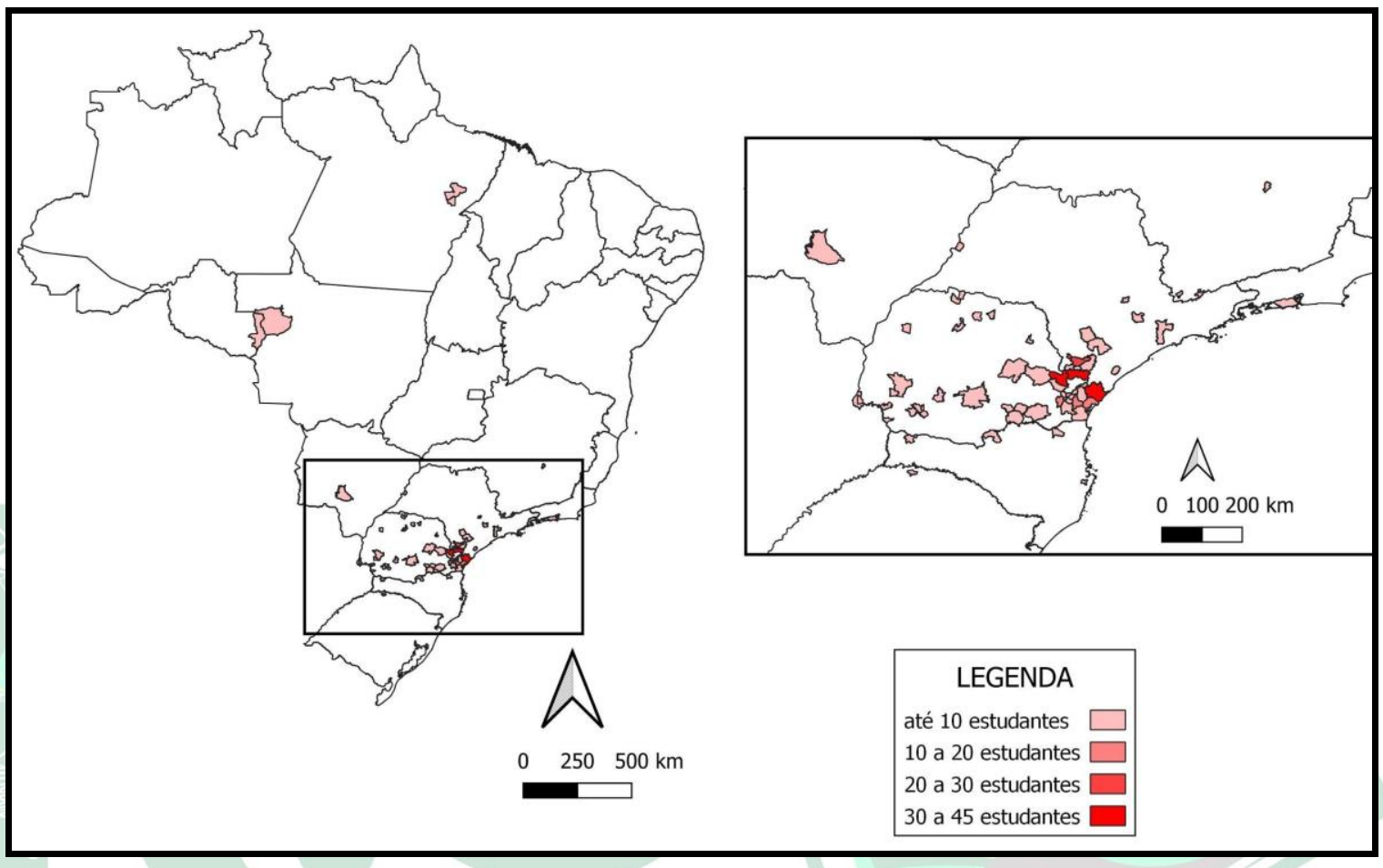

Figura 1 - Distribuição territorial domiciliar dos estudantes da LECAMPO UFPR com base nos dados do Censo da Educação Superior de 2009 a 2018 (INEP-MEC) (MELZER, 2020).

O que podemos perceber na análise espacial da LECAMPO é que o curso atua com uma multiplicidade de territórios onde os estudantes estão inseridos. Nesta lógica itinerante o curso atende a outros territórios para além da sua área de ação que seria o litoral paranaense. Atualmente, há uma demanda represada no estado de São Paulo, devido à ausência de LEDOCS na região. O curso atende a quilombolas, indígenas, caboclos, faxinalenses, ribeirinhos, pescadores artesanais do continente e das ilhas, agricultores familiares e camponeses tradicionais, militantes de movimentos sociais do campo, assentados e acampados da reforma agrária. Assim, compreende-se que a proposta da Lecampo carrega na sua constituição uma diversidade camponesa importante para a formação dos educadores em educação do campo.

Porém, vale ressaltar que devido a estratégia de ação da alternância e da itinerância os educandos do curso da LECAMPO ficaram de certa forma isolados do 
restante do Setor, funcionando geralmente nos momentos de recesso das aulas e nos finais de semana, dias em que os estudantes dos outros cursos do Setor Litoral não estão com aulas, aparentando uma certa invisibilidade do curso, com seus discentes e docentes.

É dentro desta organização de curso que se constrói o NID Educação do Campo com uma proposta que amplia o grupo de escolas atendidas, por meio da estratégia de alternância pedagógica, organizado por meio do estímulo à docência na área do ensino de ciências, com uma ênfase maior ao ensino de química e física, na proposta do diálogo de saberes e debate de poderes (QUIJANO, 2005). Tendo como eixos de ação principal de fazer os saberes comunitários dialogarem com os científicos por meio de cinco estratégias de ação concreta na realidade material escolar, as quais são: (a) experimentação; (b) história e filosofia das ciências; (c) ciência e arte; (d) agroecologia e (e) ludicidade.

Assim, a partir desta construção pedagógica e metodológica de trabalhar em sintonia com os tempos pedagógicos da LECAMPO no sistema do regime de alternância e na itinerância, optou-se por desenvolver o atendimento às escolas selecionadas pela SEED-PR ${ }^{2}$ ao PIBID no Tempo Universidade (TU) e no Tempo Comunidade (TC) dando prioridade para o desenvolvimento dos planos de trabalho de cada bolsista, envolvendo os saberes comunitários, numa ação direta com as escolas em cada uma das localidades de residência dos bolsistas. Desta forma, no TU foi construída e realizada uma ação coletiva com os colégios estaduais do campo Hiram Rolim Lamas, localizado na vila da Copel em Antonina, e o Colégio Ilha das Peças, localizado na Ilha das Peças em Guaraqueçaba. Já no TC a ação foi desenvolvido em um conjunto de escolas localizadas nas comunidades dos estudantes, são elas: Colégio Estadual Indígena M'bya Guarani (aldeia Araçaí em Piraquara, PR), Escolas municipais em Apiaí no estado de São Paulo, Colégio Estadual Quilombola Diogo Ramos localizado no quilombo João Surá em Adrianópolis, Escolas próximas à área de assentamento da reforma agrária Zumbi dos Palmares no Estado de São Paulo, Colégio Estaduais e Municipais das Ilhas sob a organização do Núcleo Regional de Educação (NRE) de Paranaguá-PR e com Colégios da Rede Municipal em Tijucas do Sul-PR. O mapa na

${ }^{2}$ Secretaria Estadual de Educação do Paraná. 
sequência dá uma ideia da extensão territorial das ações em TU e TC do PIBID NID

Educação do Campo:

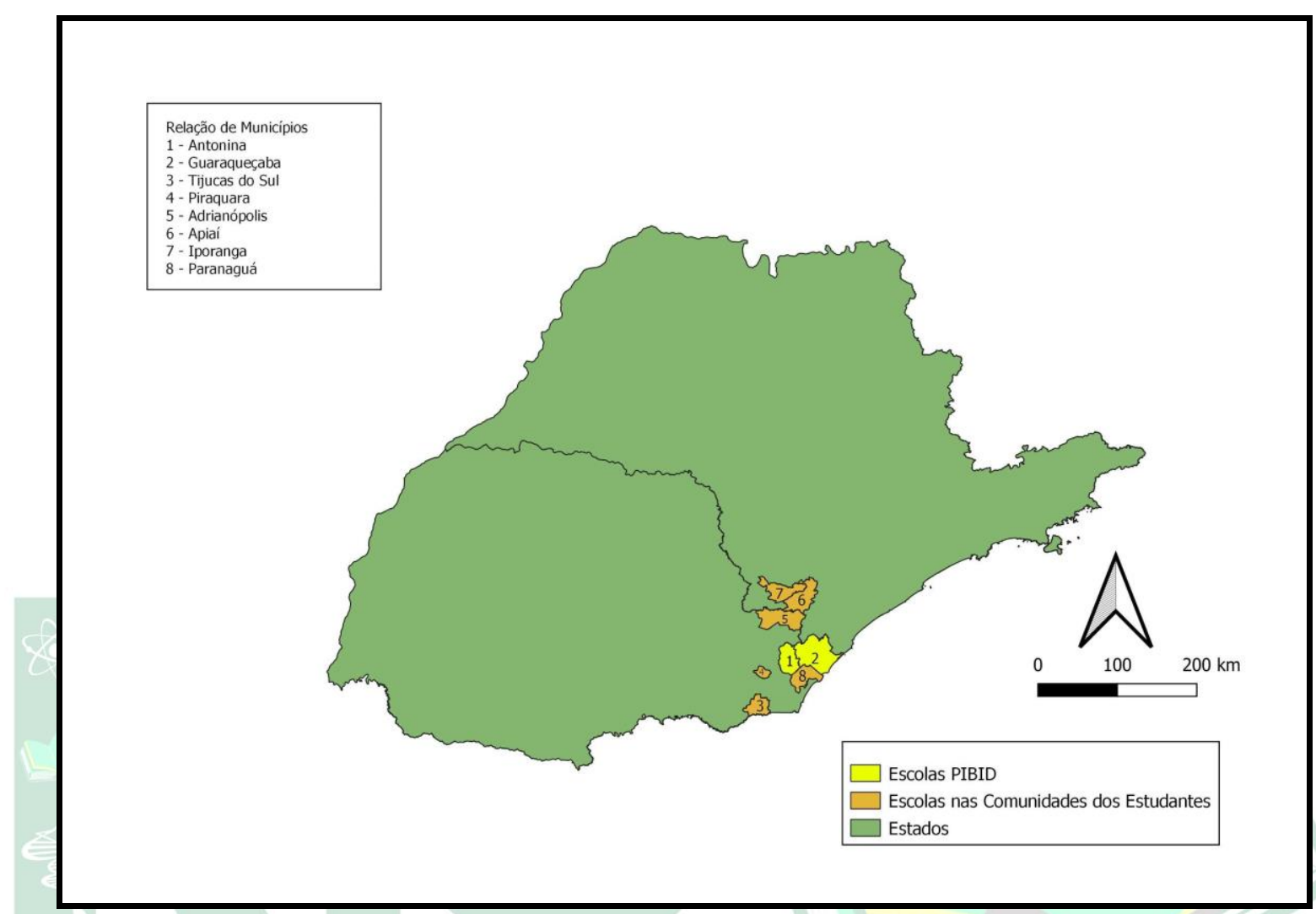

Figura 2 - Distribuição geográfica do PIBID NID Educação do Campo. Fonte: os autores (2020).

Desta forma, um ponto positivo com relação a proposta é que houve um substancial ampliação do espectro de ação do projeto, criando possibilidades pedagógicas diferenciadas e intercâmbios de saberes entre diferentes tipos de comunidades camponesas, indígenas e quilombolas. Se fizermos o levantamento da composição da equipe de bolsistas dos projetos teremos o seguinte gráfico: 


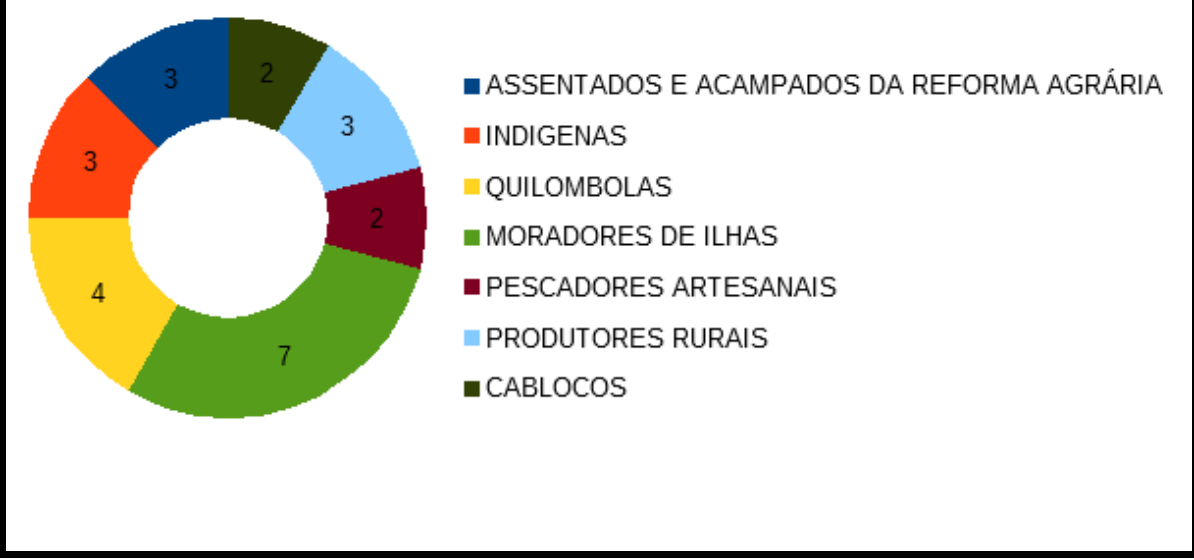

Figura 3 - Composição dos bolsistas PIBID NID Educação do Campo. Fonte: os autores (2020).

Olhando para o gráfico na figura 3 podemos compreender que há uma diversidade na formação da equipe de bolsistas no projeto, refletindo a diversidade docente da LECAMPO. Este ponto é importante frisar uma vez que é na diversidade que se cria as possibilidades teóricas e metodológicas para construção de diálogo de saberes. Neste sentido, esta diversidade de culturas, princípios e visões de mundo contribuiu para o pleno desenvolvimento da proposta do diálogo de saberes e debate de poderes na educação nos mais variados contextos comunitários de ação do projeto.

\section{ETNOPEDOLOGIA E O DiÁlogo DE SABERES PARA A CONSTRUÇÃO DA AGROECOLOGIA}

A Educação do Campo atua com bases teóricas e concepções antagônicas ao modelo imposto pelo agronegócio pautado na perspectiva empresarial e na lógica industrial capitalista (CALDART, 2016). O agronegócio prioriza a agricultura de poucos cultivares voltados à comercialização, tem como princípios a monocultura, exploração dos trabalhadores e dos recursos naturais visando o lucro máximo. Segundo Machado e Machado Filho (2014) esse modelo traz consequências degradantes ao ambiente e aos povos do campo, das águas e das florestas, devasta florestas nativas, contamina as águas, degrada a qualidade do solo e extingue saberes culturais ou saberes tradicionais, como geralmente são denominados na academia.

Para contrapor o modelo agrícola imposto pelo capital a Educação do Campo adota os princípios e diretrizes da Agroecologia, que originalmente emergiu como uma 
ciência acadêmica alternativa dentro das ciências agrárias (CAPORAL;

COSTABEBER, 2004). Mas, atualmente é compreendida por muitos estudiosos como um campo de conhecimento humano que busca compreender toda a complexidade socioambiental para promover ações de transformação da realidade tanto no campo como na cidade (MACHADO; MACHADO FILHO, 2014). Ou seja, podemos considerar a agroecologia como um movimento científico e sociocultural que busca religar a humanidade com a natureza do planeta.

Na agroecologia o diálogo de saberes é um princípio básico para a construção do seu conjunto teórico-metodológico (ALTIERI, 2002), ou, em outras palavras, o diálogo de saberes é um procedimento elementar da epistemologia agroecológica. No viés agroecológico, é preciso fazer uma integração dos conhecimentos estabelecidos nos diferentes campos científicos com os conhecimentos culturais-históricos construídos pelos povos do campo, das águas e da floresta, para então constituir saberes que podem ajudar no entendimento dos complexos processos inerentes à realidade socioambiental local e global. Por sua vez, esses saberes agroecológicos podem orientar as ações humanas harmonizadas com os processos naturais e contribuir na religação dos seres humanos com o planeta Terra (MACHADO; MACHADO FILHO, 2014). Portanto, distintamente da lógica do agronegócio, a agroecologia considera e valoriza toda a biodiversidade e a diversidade dos saberes étnicos estabelecidos ao longo da história humana.

Neste contexto, a diversidade cultural-histórica da equipe envolvida no planejamento e nas ações do PIBID favoreceram a efetivação do Diálogo de Saberes. Contudo, para promover o diálogo e as atividades dentro do escopo do PPC da LECAMPO foi definido um recorte temático em torno dos conceitos da ciência do solo, principalmente devido a multiculturalidade presente no coletivo, onde cada participante se expressava a partir dos saberes de sua comunidade, o que dificulta o compartilhamento de conceitos e pode superficializar a comunicação criando obstáculos para a ocorrência do diálogo de saberes entre a comunidade Lecampo e as comunidades escolares envolvidas. Neste sentido, o solo corresponde num elemento articulador que pode potencializar o diálogo de saberes para trabalhar os conceitos e conteúdos das ciências da natureza dentro dos princípios e diretrizes da Agroecologia. Visto que o solo é a base de vida das comunidades camponesas, inclusive dos povos das águas e das 
florestas (MAZOYER; ROUDART, 2010) e, além disso, os trabalhos etnopedológicos publicados mostram que todas as comunidades tradicionais estudadas nos cinco continentes do globo estabeleceram saberes pedológicos (TOLEDO; BARRERABASSOLS, 2015).

A proposta do diálogo de saberes tem como objetivo propiciar uma relação dos saberes dominadores, a visão do colonizador, com os conhecimentos de base local e comunitária (SANTOS, 2003). Quijano (2005) compreende que há uma relação de poderes na hierarquia de saberes. Busca-se romper com a hierarquização dos saberes trazendo os saberes sujeitados, aqueles produzidos nos seios das comunidades, para dialogar com os saberes dominadores, aqueles oriundos da tradição secular do colonizador, que a escola tradicional transmite e difunde nas diversas comunidades. Desta forma, a partir de um processo de confrontamento e discussão, dialética, originam-se novas abordagens de conhecimentos que trazem os saberes escolares científicos em diálogo com o saber comunitário; contribuindo para o fortalecimento da identidade local e para o envolvimento dos jovens com a história, tradições e perspectiva local em detrimento ao universal e global.

Assim, tendo o solo como tema foi possível iniciar um diálogo de saberes etnopedológicos, primeiro por dentro da equipe do PIBID e depois com as comunidades escolares envolvidas nas ações. Cabe ressaltar que a Etnopedologia consiste num campo acadêmico interdisciplinar, que traz em sua vertente epistemológica pressupostos da Etnografia Antropológica, Linguística, História, Geografia e Ciência do Solo, voltado especificamente para o estudo das relações humanas com o solo partindo dos saberes pedológicos que emergem desta relação (ALVES; MARQUES, 2005). Portanto, um campo teórico-metodológico interessante e relevante para promover o diálogo de saberes a partir de conceitos sobre o solo (TOLEDO; BARRERA-BASSOLS, 2015). No nosso caso, a etnopedologia possibilitou a construção de conceitos da ciência do solo comuns aos educandos participantes do PIBID, o que facilitou nos momentos de planejamento e realização das ações.

\section{A CONSTRUÇÃO DA OFICINA SOLO COMCIÊNCIA}

A partir da proposta de ação do NID Educação do Campo há de se fazer algumas considerações sobre a compreensão espacial do entorno escolar das escolas do campo 
Hiram Rolim Lamas e Ilha das Peças. Inicialmente, o Colégio Estadual do Campo Hiram Rolim Lamas fica localizado dentro das dependências da COPEL, Usina Parigot de Souza, em Antonina. Esta unidade educacional atende um grupo de comunidades camponesas que vivem do turismo e da produção de hortaliças e leguminosas. Uma característica do perfil discente desta escola está em situação de vulnerabilidade socioeducacional, necessitando de um maior apoio dos professores, pedagogos e diretores.

Já o colégio estadual do campo Ilha das Peças, situado em Ilhas das Peças no município de Guaraqueçaba, tem uma situação diferenciada de atendimento dos residentes na ilha que são majoritariamente moradores que vivem do turismo e pescadores artesanais que vivem da produção pesqueira. Porém, uma das questões que a escola lida, assim como a comunidade, está relacionada com as restrições colocadas pelos órgãos de fiscalização ambiental e pela força verde que está na proibição das atividades extrativista como corte de árvores, poda, dentre outros e na proibição do plantio para autoconsumo, ou seja, os moradores são proibidos pelo estado de plantar nos quintais das suas casas os cultivares que utilizam para alimentação familiar, devido às legislações ambientais e a atuação dos órgãos de fiscalização que não compreendem os moradores como parte do ecossistema nas ilhas.

É neste contexto sócio territorial que os debates e o desenvolvimento das atividades sobre solos na escola que se desenvolveu no âmbito de um planejamento coletivo com as duas unidades escolares, ouvindo as demandas das equipes pedagógicas e fazendo as adaptações necessárias para a construção da atividade. Neste processo de escutatória das necessidades das comunidades escolares foi levantado a necessidade de discussão do tema alimentação saudável que foi inserido e correlacionado com a temática dos solos. Assim, esta ação desenvolveu-se em três etapas que consistiram em: 1) planejamento coletivo com as unidades escolares; 2) desenvolvimento da oficina Solo Comciência e 3) Ação pedagógica na escola com os bolsistas PIBID em sala de aula e uma palestra ministrada por um educador da área de Agroecologia sobre alimentação saudável.

Nesta lógica, a primeira etapa consistiu em um conjunto de reuniões com os professores supervisores e equipe pedagógicas no espaço escolar para trocar ideias sobre ações a serem desenvolvidas e sobre as necessidades que o espaço territorial 
demanda para o desenvolvimento das atividades do PIBID. Nestas reuniões foi definido o formato de organização e calendário escolar para desenvolvimento da ação pedagógica ${ }^{3}$.

A segunda etapa consistiu no desenvolvimento de uma oficina pedagógica com o tema dos solos nomeada de Solo Comciência que buscou abordar com estudantes os saberes comunitários sobre solos e alguns conceitos da Etnopedologia. A oficina consistiu na apresentação de material audiovisual, roda de conversa sobre a importância dos solos e experimentação com a preparação de perfis de solos para compreender conceitos físicos-químicos relacionados a percolação da água.

A terceira etapa consistiu no desenvolvimento dos conceitos químicos, físicos e biológicos relacionados aos solos e os saberes etnopedológicos. Todas as interações em sala de aula dos bolsistas foram feitas com os professores supervisores nas respectivas turmas.

Ao final do processo foi constituída uma avaliação da proposta de ação pedagógica e do PIBID como um todo em cada unidade escolar. O que podemos compreender desta ação é que a repercussão com os estudantes, com os professores e com a direção da escola foi positiva. Ao final do processo para prover um encerramento a atividade foi apresentada uma oficina sobre alimentação saudável aos estudantes das unidades escolares apresentada por um professor da área de Agroecologia do Setor Litoral.

A partir desta primeira inserção com o PIBID foi possível construir uma relação de proximidade e parceria com as escolas. As atividades fomentaram a intenção de conduzir experimentos com hortas agroecológicas para dar continuidade a ação pedagógica no Colégio Estadual do Campo Hiram Rolim Lamas. No Colégio Estadual do Campo Ilha das Peças foi proposto a continuidade das inserções com outras propostas de diálogo de saberes que busquem trazer os saberes comunitários da ilha para dentro da sala de aula em parceria com os saberes científicos.

${ }^{3}$ Vale ressaltar que o tema solo foi definido como tema base de trabalho de um coletivo de bolsistas que com a orientação de um professor da área de Agroecologia desenvolveram as atividades nas unidades educacionais de Antonina e Ilha das Peças. 


\section{O DIÁlOGO DA QUÍMICA, FÍSICA E BIOLOGIA COM O ESTUDO SOBRE SOLOS E SEGURANÇA ALIMENTAR}

Além do compartilhamento de conceitos pedológicos, o estudo sobre os saberes do solo coloca o educando em contato com os conceitos da química, física e biologia que são inerentes ao conjunto teórico da ciência do solo.

A partir das propostas trabalhadas na oficina Solo Comciência foi possível desenvolver um processo de diálogo de saberes comunitários sobre solos que foram levantados a partir do conhecimento acumulado e do levantamento realizado com comunidades ribeirinha, rurais e quilombolas. São esses solos:

a) Pedregoso $\rightarrow$ cascalho, pedregoso e rochoso; b) Saibro; c) Arenoso $\rightarrow$ areia e várzea; d) Terras $\rightarrow$ gorda, mista, preta, roxa e vermelha; e) Argilosos; f) Massapês $\rightarrow$ preto e vermelho e g) Barros $\rightarrow$ branco, cinza e vermelho (BUENO et all, 2017).

O que pudemos perceber foi que muitos dos solos apresentados e que foram inventariados a partir de história oral em várias comunidades eram de conhecimento dos estudantes. Para além disso, foram trabalhadas atividades práticas de montagens de modelos de coberturas de solos com o intuito de explicar as suas funções no ciclo e no processo de filtragem da água, as imagens a seguir mostram o desenvolvimento desta experimentação:

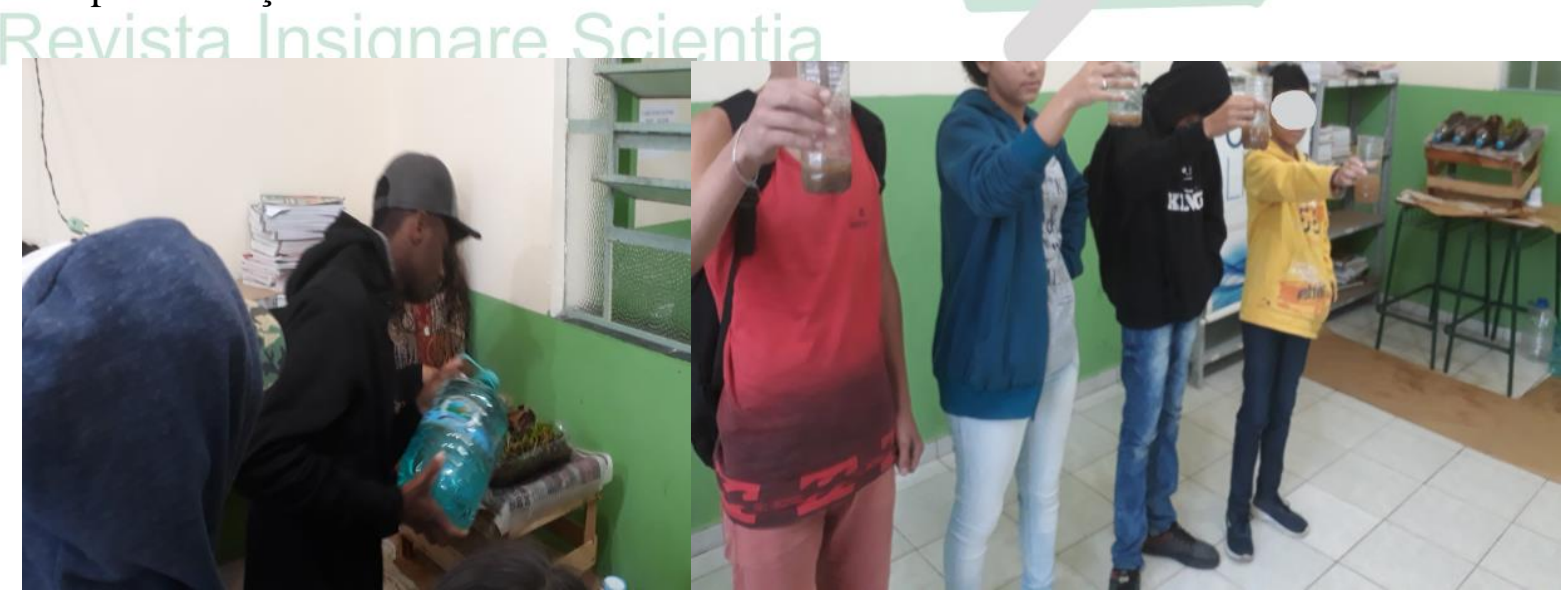

Figura 4 - Desenvolvimento da atividade prática sobre solos no ciclo de filtragem da água durante a oficina no Col. Estadual do Campo Hiram Rolim Lamas. Fonte: os autores (2020).

A partir desse levantamento dos saberes comunitários e da atividade prática foi possível estabelecer relações com a química, física e biologia articulando com as propriedades dos solos constantes nos inventários populares. Para a química estabeleceu-se a relação entre os processos químicos envolvidos na agregação, na acidez 
e fertilidade do solo trazendo os conceitos de ácido-base, $\mathrm{pH}$, propriedades dos elementos químicos, distribuição eletrônica com o conceito de cátions e ânions e os saberes escolares relativos a filtragem das impurezas e separação de misturas. Ou seja, a partir do saber de solos pode-se abordar a sua relação com a química atômica, mostrando a relação da química eletrônica com o saber comunitário de solos adquirido por gerações com o manuseio da terra.

$\mathrm{Na}$ física foram desenvolvidas relações de diálogo entre as características de resistência dos agregados ao impacto das gotas de chuva e energia da água no escoamento superficial, também da atuação das raízes e dos poros do solo na percolação da matéria orgânica (especialmente do elemento Carbono - C) e infiltração da água no solo, articulando com a física newtoniana de partículas e a força da gravidade. Ou seja, pode-se inserir o estudo da física nas questões relativas à organização da estrutura dos solos e os movimentos que estas desenvolvem dentro do agregado, sendo possível desenvolver de forma contextualizada os conceitos referentes à cinemática Newtoniana com o movimento particular.

$\mathrm{Na}$ biologia relacionou-se a questão da vida nos solos e a importância dos microrganismos e da interação solo-planta na formação, estabilização e retenção da matéria orgânica, fixação de Nitrogênio e disponibilidade do fósforo no interior do solo. Tendo como base a fertilidade de um solo com intensa atividade biológica foi possível abordar a questão relacionada a segurança alimentar e alimentação saudável, relacionando a importância do cultivo biodiverso como o sistema agroflorestal, que favorece a produção de alimentos em todos os períodos do ano, conjuntamente com plantas frutíferas e madeiráveis, potencializando a autonomia e a manutenção da soberania alimentar das famílias camponesas e evitando os impactos negativos causados pelo Agronegócio, com sua lógica de monocultura de extensão e dependência na utilização de adubos solúveis e dos agrotóxicos, adventos tecnológicos de guerra que foram a base da Revolução Verde.

Assim, a tipologia de solos construída no levantamento comunitário e analisada com os estudantes foi relacionada a partir das propriedades química, física e biológicas com os conceitos descritos para cada disciplina escolar. O mapa conceitual a seguir dá uma visão geral deste processo de construção: 


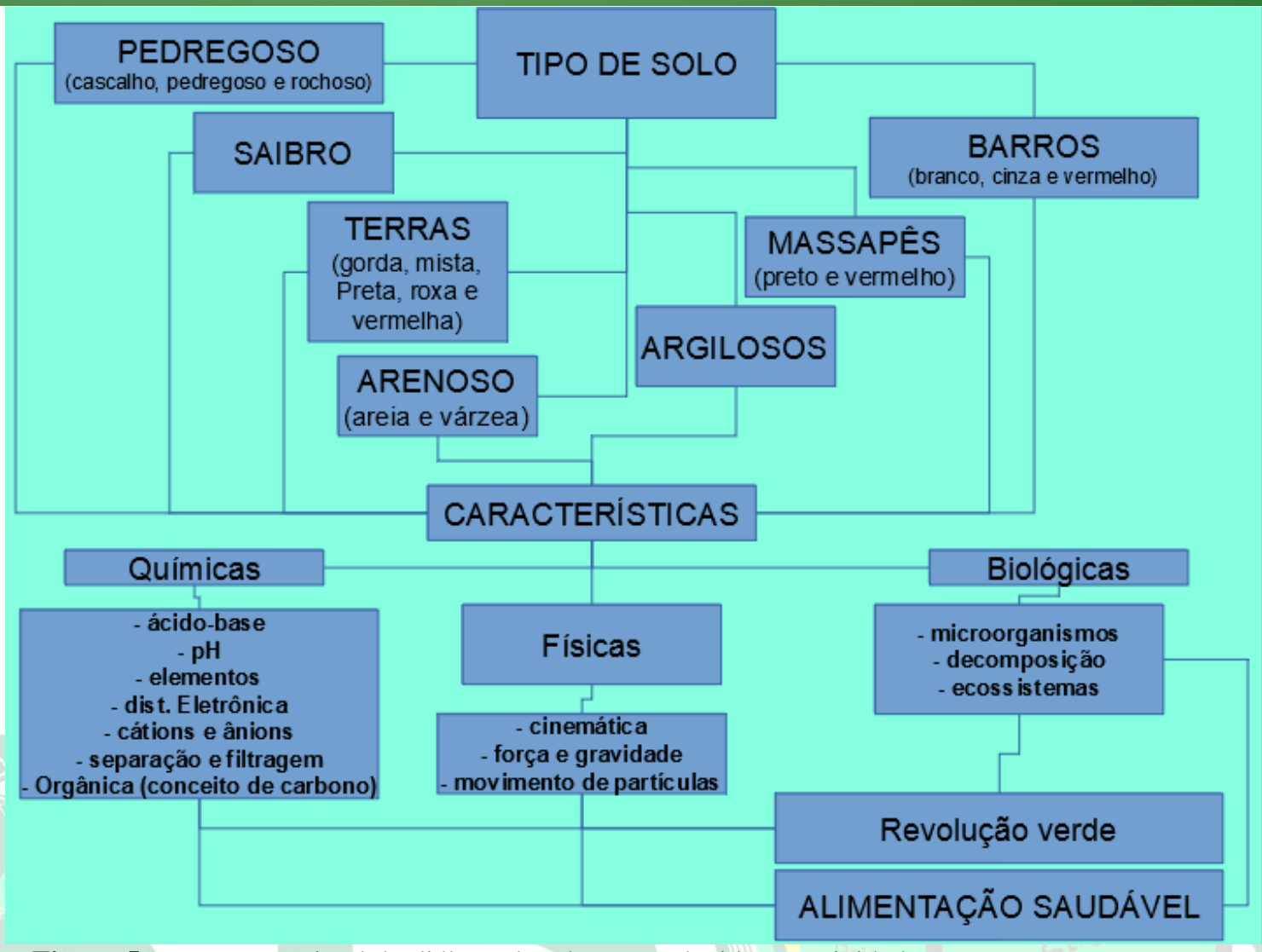

Figura 5 - Mapa conceitual do diálogo de saberes produzidos na atividade proposta. Fonte: os autores (2020).

A partir dos diferentes tipos de solos identificados pelos estudantes durante a oficina foram trabalhos as características física, química e biológicas relacionando-as com os saberes escolares e a sua importância na análise das características físicoquímicas de cada tipo de solo, suas utilizações e possibilidades produtivas. Nesta ação os estudantes foram compreendendo como os saberes científicos se materializavam na relação direta com o conhecimento empírico organizado do levantamento etnopedológico desenvolvido por Bueno et all (2017). Ou seja, a partir da prática e das aulas, após a oficina realizada na escola, os estudantes conseguiram relacionar os saberes passados pelos seus pais e avos nas comunidades com os conhecimentos científicos. A partir destas compreensões foi possível inserir conceitos de agroecologia e fazer discussões críticas a partir do perigo eminente a natureza por conta da utilização de agrotóxicos e outros produtos químicos e biológicos advindos da revolução verde. Também foi discutido com os estudantes os aspectos históricos da revolução e os seus impactos nos ambientes rurais atuais com a discussão sobre a qualidade da alimentação e a sua relação direta com um solo saudável. 
A partir do desenvolvimento de todo o processo educacional pudemos perceber que os estudantes conseguiram compreender as relações existentes entre os saberes levantados empiricamente sobre os solos e suas características com os saberes científicos organizados pela química, física e biologia. Neste sentido, os estudantes compreenderam que os conceitos escolares se materializam na realidade a partir de algumas características únicas dos diferentes tipos de solos.

No processo avaliativo da atividade também foi percebido um engajamento dos estudantes nas aulas e a construção de um processo de empoderamento dos saberes oriundos de suas comunidades que foram relacionados, a partir das aulas com os bolsistas e supervisores, com os conhecimentos das disciplinas científicas escolares. Também foi colocado no processo de avaliação que os estudantes constataram que o saberes escolares possuem uma materialidade que se relaciona com os conhecimentos trabalhados pelos seus familiares nas comunidades atendidas pelas duas escolas.

\section{CONSIDERAÇÕES FINAIS}

Este artigo teve como objetivo fazer uma apresentação de uma atividade desenvolvida no âmbito do PIBID no NID Educação do Campo. O que podemos compreender é que este tipo de atividade promovida potencializa a relação ternária entre escola, universidade e comunidade. Ao final da proposta fizemos a avaliação da ação pedagógica com os estudantes das escolas e as equipes pedagógicas, a devolutiva destes foi positiva, mostrando que a proposta desenvolvida foi diferenciada e potencializadora de novas abordagens do Ensino de Ciências na Escola do Campo.

Vale ressaltar que a partir do PIBID NID Educação do Campo originou-se o Laboratório de Estudos em Ludicidade, Tecnologia e Comunicação (LUTECOM) que tem como objetivo continuar desenvolvendo por meio da pesquisa, ensino e extensão a relação do curso com as comunidades. Neste momento, após avaliação das propostas do PIBID estamos organizando materiais didáticos que ficarão disponíveis na página do laboratório: www.lutecom.ufpr.br.

Assim, concluímos este escrito mostrando as potencialidades desta proposta que rompeu com os muros da universidade, levando o intercâmbio comunitário com o conjunto de saberes comunitários para dentro das escolas do campo.

\section{AGRADECIMENTOS}


Gostaríamos de agradecer o apoio da CAPES no desenvolvimento deste projeto no que toca ao financiamento desta e de outras ações do PIBID a partir da liberação de bolsas de iniciação à docência, supervisão e coordenação do NID Educação do Campo. Também agradecemos pelos valores liberados a partir do edital PRÓ LICENCIATURAS que aportaram financeiramente as necessidades técnicas de deslocamento e materiais ao desenvolvimento das propostas pedagógicas.

\section{REFERÊNCIAS}

ALTIERI, Miguel. Agroecologia: bases científicas para uma agricultura sustentável. Guaíba: AS-PTA/Agropecuária. 2002. 592p.

ALVES, Ângelo Giuseppe Chaves; MARQUES, José Geraldo Wanderley. Etnopedologia: uma nova disciplina? Em: Tópicos em Ciência do Solo. Viçosa: Sociedade Brasileira de Ciência do Solo; 2005. p. 321-344.

BUENO, Orlanda Terezinha Martins. DAHMER, Gilson Walmor. SILVA, Thayanne Straub Jesus da. MELZER, Ehrick Eduardo Martins. Diálogos de Saberes na Educação do Campo: observando os saberes etnopedológicos em Cerro Azul (PR). Florianópolis: ANAIS do XI Encontro Nacional de Pesquisa em Educação em Ciências - XI ENPEC. 2017.

CALDART, Roseli Salete. Escolas do Campo e Agroecologia: uma agenda de trabalho com a vida e pela vida! Setor de Educação do Movimento dos Sem Terras (MST), Instituto Educacional Josué de Castro, Veranópolis, RS. 2016.

CAPORAL, Francisco Roberto; COSTABEBER, José Antonio. Agroecologia: alguns conceitos e princípios. Brasília: MDA/SAF/DATER-IICA, 2004.

MACHADO, Luis Carlos Pinheiro; MACHADO FILHO, Luis Carlos Pinheiro. A dialética da agroecologia: contribuição para um mundo com alimentos sem veneno. São Paulo: Expressão Popular, 2014. 360p

MAZOYER, Marcel; ROUDART, Laurence. História das agriculturas no mundo: do neolítico à crise contemporânea. São Paulo: Unesp, 2010.

MELZER, Ehrick Eduardo Martins. O movimento da política educacional PROCAMPO: uma análise das licenciaturas em educação do campo na região Sul do Brasil. 2020. 341 f. Tese (Doutorado em Educação) - Programa de Pós Graduação em Educação, Universidade Federal do Paraná, Curitiba.

SANTOS, B. S. Para uma Sociologia das Ausências e uma Sociologia das Emergências. In: SANTOS, B. S. (Org.). Conhecimento prudente para uma vida decente: "Um discurso sobre as Ciências" revisitado. Porto: Afrontamento, 2003. p. 735-775. 
SANTOS, Clarice Aparecida dos. Educação do campo e políticas públicas no Brasil: A instituição de políticas públicas pelo protagonismo dos movimentos sociais do campo na luta pelo direito a educação. 2009. 109 f. Dissertação (Mestrado em Educação do Campo) - Programa de Pós Graduação em Educação, Universidade de Brasília, Brasília.

QUIJANO, Anibal. Colonialidad del poder, eurocentrismo y América Latina. In: LANDER, Edgardo. La colonialidad del saber: eurocentrismo y ciencias sociales. Buenos Aires: CLACSO. 2005, p. 117-142.

TOLEDO, Victor Manuel.; BARRERA-BASSOLS, Narcizo. A Memória Biocultural: a importância ecológica dos saberes tradicionais. São Paulo, SP.: Expressão Popular, 2015.

UFPR LITORAL. Projeto Político Pedagógico Setor Litoral. Disponível em: <http://www.litoral.ufpr.br/portal/wp-content/uploads/2015/02/PPP-UFPRLITORAL_Set-2008_Alteracao_Dez-2008.pdf > . Acesso em 28/12/2014.

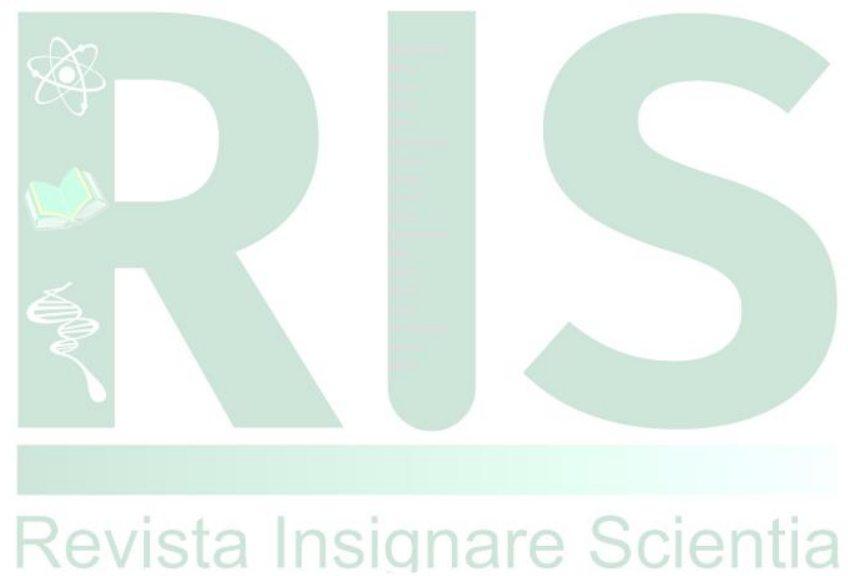

